\title{
中国英文科技编辑行业规范 倡议书
}

近 20 年，随着中国科学研究飞速发展，科研成果在不断增加，发表在英 文学术期刊上的科研论文在质和量上都有实质性突破。这些成就主要归功于良 好的科研环境和广大科研人员的刻苦和勤奋，同时也得益于逐步发展和成熟的 英文科技论文编辑行业。

英文学术期刊是国际学术交流的平台，成果往往只有发表在英文学术期刊 上才能得到国际学术界的认可。然而, 很多中国科研人员限于英语写作能力, 无力将其科研成果发表在英文学术期刊上，他们必须借助于母语为英文的、具 备专业知识和学术水平的专家, 或拥有强大专家库的英文科技编辑公司（以下 简称编辑公司）的支持。

目前，在中国注册和未注册的编辑公司上千家，他们的服务理念、形式和 内容迥异，服务质量良莠不齐。有些编辑公司鱼目混珠，完全以欺骗为手段， 以谋取暴利为目的。更有部分论文编辑公司违反科研伦理和学术规范, 放任、 纵急甚至参与和操纵学术不端行为, 不仅严重影响了英文科技论文编辑行业的 声誉，更严重损害了中国科研人员在国际上的信誉和在英文学术期刊上发表论 文的公平性。

“人无诚信不立，业无诚信不兴，国无诚信不强”。为了促进中国英文科 技编辑行业的健康发展，加强行业自律和监督，以切实将中国科研成果走向世 界提供高质量的论文语言服务，预防和避免任何形式的学术不端行为，我们 现宣布成立中国英文科技论文编辑联盟（The Alliance for Scientific Editing in China，ASEC），并正式倡议，制订和执行中国英文科技论文编辑行业规范（以 下简称本规范）。所有正式在中国注册的编辑公司均可申请加人 ASEC, 并由 其负责人签署本规范。签署本规范的编辑公司必须将本规范纳人到公司的政策 和实际操作流程并严格执行。

本规范包括，但不限于以下原则 :

第一，作者必须对论文学术内容负全责：根据国际医学杂志编辑委员会 ( ICMJE) 标准, 论文的学术内容必须是作者的研究成果, 因此, 必须由作者确认;

第二，只由培训合格的编辑处理文稿;

第三，不得篡改供科研数据或为作者伪造实验数据;

第四，坚决拒绝作者提出的任何违反科研伦理和学术规范的要求，并说明 
学术不端可能给作者科研和学术生涯造成永生影响;

第五，不得向作者提供虚假或虚构的同行评审专家信息;

第六，不得从事任何形式的科研论文买卖行为;

第七, 不得直接或间接参与国家有关部门和科研单位所公布的各类学术不 端行为;

第八，严格保密作者提供的任何个人信息与文稿信息以及与作者的任何沟 通;

第九，如作者在论文中对编辑公司在文稿撰写过程中给予帮助的致谢，应 欣然接受, 并视之为对研究内容和文稿质量的高度信心;

第十, 签署本规范是一种信任和荣誉, 更是一种责任和承诺。所有签署本 规范的编辑公司必须遵守本规范。违者将从 ASEC 除名。

这份倡议书在 2015 年 10 月 $17 \sim 18$ 日举行的 “第一届国际医学研究与发 表高峰论坛” 公布。签署本规范的编辑公司名单将公示在 ASEC 官方网站和杂 志《医学研究与发表》上。

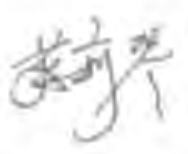

蔡莉琴 意得辑 (Editage) 中国区营 运总监

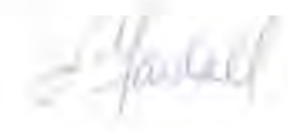

Lindsey Gendall, Accdon-LetPub LLC 执行编辑

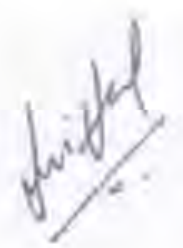

Sharad Mittal, 英论阁 C Crimson Interactive Pvt Ltd) 首席执行官,

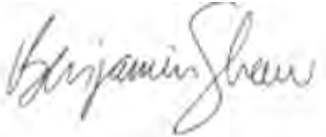

Benjamin Shaw (本杰明), 理文 编辑 (Edanz China) 首席运营 官兼中国区总监

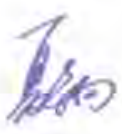

夏华向 美捷登生物科技有限公司 主 席

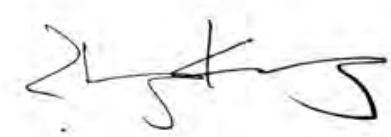

张科宏 长青藤编辑中国区编辑部执 行总裁 